\title{
Environmental variation mediates the prevalence and co-occurrence of parasites in the common lizard, Zootoca vivipara
}

\author{
Qiang $\mathrm{Wu}^{1,2} \mathbb{D}$, Murielle Richard ${ }^{1 *}$, Alexis Rutschmann ${ }^{1,2,3}$, Donald B. Miles ${ }^{1,4}$ and Jean Clobert ${ }^{1}$
}

\begin{abstract}
Background: Hosts and their parasites are under reciprocal selection, leading to coevolution. However, parasites depend not only on a host, but also on the host's environment. In addition, a single host species is rarely infested by a single species of parasite and often supports multiple species (i.e., multi-infestation). Although the arms race between a parasite and its host has been well studied, few data are available on how environmental conditions may influence the process leading to multiple infestations. In this study, we examine whether: (1) environmental factors including altitude, temperature, vegetation cover, human disturbance, and grazing by livestock affect the prevalence of two types of ectoparasites, mites and ticks, on their host (the common lizard, Zootoca vivipara) and (2) competition is evident between mites and ticks.

Results: We found the probability of mite infestation increased with altitude and vegetation cover, but decreased with human disturbance and presence of livestock. In contrast, the probability of tick infestation was inversely associated with the same factors. Individuals with low body condition and males had higher mite loads. However, this pattern was not evident for tick loads. The results from a structural equation model revealed that mites and ticks indirectly and negatively affected each other's infestation probability through an interaction involving the environmental context. We detected a direct negative association between mites and ticks only when considering estimates of parasite load. This suggests that both mites and ticks could attach to the same host, but once they start to accumulate, only one of them takes advantage.

Conclusion: The environment of hosts has a strong effect on infestation probabilities and parasite loads of mites and ticks. Autecological differences between mites and ticks, as indicated by their opposing patterns along environmental gradients, may explain the pattern of weak contemporary interspecific competition. Our findings emphasize the importance of including environmental factors and the natural history of each parasite species in studies of hostparasite coevolution.
\end{abstract}

Keywords: Parasites, Co-occurrence, Competition, Environmental mediation, Common lizard

\section{Background}

A parasite lives in or on the host, feeds on the host, shows some degree of adaptation to the host and usually does not cause immediate death of the host [1]. Parasites can alter various attributes of their hosts including behavior, physiology, and life history as well as modify patterns of

\footnotetext{
${ }^{*}$ Correspondence: murielle.richard@sete.cnrs.fr

${ }^{1}$ CNRS, Station d'Ecologie Théorique et Expérimentale, UMR 5321 and Université Toulouse III-Paul Sabatier, 09200 Moulis, France

Full list of author information is available at the end of the article
}

sexual selection and population dynamics $[2,3]$, which in turn may influence host-parasite coevolution [4]. On the other hand, hosts may evolve defense strategies to mitigate the negative effects of parasites, including parasite avoidance behavior, immunity, resistance, and tolerance [5-7]. However, host defenses are not the only barrier to parasitic exploitation; multiple infections by different parasite species can also affect host-parasite dynamics $[8,9]$. Since a host can be considered a finite resource for parasites [10], one can predict that either intra- or 
inter-specific competition occurs among parasites sharing the same host species. For example, in a manipulative study, one flea species exhibited reduced developmental success in the presence of a competing species during a food shortage [11]. In addition to food resources, studies of 'crowding effect', i.e. the size of parasites is inversely proportional to the number of parasites in a given infection, suggest that alternative limiting factors may also affect competitive interactions between parasites. Such factors may include oxygen or space, as observed in a study on tapeworms [12]. The majority of evidence supporting the patterns of interspecific competition among parasites is based on endoparasite species [11], yet there is limited evidence of competition among ectoparasites. Therefore, it is of interest to investigate interspecific competition between ectoparasites and potential mediating factors (we hereafter use the term 'infestation' instead of 'infection', as 'infestation' conveys the idea of external attachment which is more appropriate for ectoparasites).

Ectoparasitic infestation is affected by both biotic attributes and characteristics of their local environment. Temperature and humidity may influence parasite activity and reproductive success $[13,14]$. Altitude, vegetation structure, and topography may alter encounter rates between hosts and parasites [13-16]. Finally, anthropogenic disturbance from climate warming [17], habitat fragmentation [18], and habitat degradation [19] may also affect host-parasite dynamics. To date, several factors mediated by anthropogenic disturbance are known to influence host-parasite relationships $[17,20]$. For example, habitat degradation from land use practices (e.g., livestock grazing) can reduce an individual's ability to resist infestation through the decline in habitat quality, food availability, and refugia [21]. Livestock can also enhance local prevalence of parasites, because of their role in supporting survival and reproduction of some parasites $[20,21]$. In addition, degradation of the thermal environment induced by climate change and habitat modification $[17,22]$ can also alter the microhabitat experienced by parasites in the off-host environment. Such environmental alternations have a cascading influence on host-parasite interactions, which can include broadening the distributional range of parasites, increasing the duration of activity of parasites, and enhancing host susceptibility through reductions in host condition $[17,23,24]$. Therefore, both natural environment and human-induced environmental variation need to be considered when analyzing the effects of parasites on host population dynamics.

Many reptile species are susceptible to infestations by ectoparasites, and mites and ticks are two of the most common ectoparasites of lizards [25]. In particular, common lizards (Zootoca vivipara) are often infested by mites of the genus Ophionyssus and sheep ticks Ixodes ricinus. Preliminary data showed that lizards exhibited the simultaneous presence of both mites and ticks at our study sites (personal observation). Thus, there is the potential for interspecific competition between these two types of ectoparasites.

Previous studies have examined the consequences of ectoparasitism on common lizards, such as the effect of host density on host-parasite interactions [26], the effect of maternal parasite load on offspring life-history traits [27], and the impact of maternal infestation on offspring performance and dispersal [28]. However, whether different environments may influence the prevalence of mites and ticks and their competitive interactions remains unknown in this species. The aim of this study is to investigate the organismal and environmental factors associated with parasite prevalence and the potential for competition between mites and ticks. We collected data on body size, body mass, and parasite infestation on common lizards from twelve populations along an altitudinal and human-induced perturbation gradient.

\section{Results}

\section{Influence of the environment on parasite infestation}

We captured a total of 775 lizards. Of these, 167 (21.5\%) individuals were infested by mites and $122(15.7 \%)$ individuals were infested by ticks, and 31 individuals (4\%) had both mites and ticks. Mite and tick prevalence also varied according to the host sex and capture year (Table 1). Mite prevalence was higher in 2014 for males and females than the other years, whereas 2012 had lower prevalence of ticks than the latter 2 years.

Based on the broken-stick criterion, only the first PC axis was retained (PC1) for further analyses. PC1 axis accounted for $63 \%$ of the total variation (Table 2). The loadings show that PC1 increased with altitude and vegetation cover, but decreased with human disturbance and grazing condition. We therefore considered positive PC1 scores to arrange sites with high vegetation and low disturbance, but negative PC1 scores represented sites with high levels of anthropogenic disturbance.

To predict the infestation probability of mites and mite load, we retained 6 and 20 models, respectively (Additional file 1: Tables S1, S2). Similarly, we kept 12 and 24 models for the infestation probability of ticks and tick load, respectively (Additional file 1: Tables S3, S4). We used the model averaging procedure to determine the variables influencing the probability of parasite infestation and parasite load.

The probability of mite infestation was positively correlated with PC1 and male sex (Table 3, Fig. 1). Thus, individuals inhabiting sites with high altitude and high amounts of vegetation cover had a greater likelihood of 
Table 1 Variation in the prevalence of mites and ticks among years

\begin{tabular}{|c|c|c|c|c|c|c|c|}
\hline \multirow[t]{2}{*}{ Parasite } & \multirow[t]{2}{*}{ Year } & \multicolumn{2}{|l|}{ Male } & \multicolumn{2}{|l|}{ Female } & \multicolumn{2}{|l|}{ Overall } \\
\hline & & Number & $\%$ & Number & $\%$ & Number & $\%$ \\
\hline \multirow[t]{3}{*}{ Mite } & 2012 & 121 & 18.2 & 165 & 8.5 & 286 & 12.6 \\
\hline & 2014 & 88 & 52.3 & 178 & 29.2 & 266 & 36.8 \\
\hline & 2015 & 53 & 18.9 & 170 & 13.5 & 223 & 14.8 \\
\hline \multirow[t]{3}{*}{ Tick } & 2012 & 121 & 11.6 & 165 & 10.3 & 286 & 10.8 \\
\hline & 2014 & 88 & 21.6 & 178 & 14.6 & 266 & 16.9 \\
\hline & 2015 & 53 & 26.4 & 170 & 18.8 & 223 & 20.6 \\
\hline
\end{tabular}

Number is the total number of individuals examined per sex (for a grand total of 262 males and 513 females) and per year. The prevalence is given as the percent of sampled individuals with either mites or ticks

Table 2 Summary of the PCA based on environmental variables

\begin{tabular}{lc}
\hline & Axis 1 \\
\hline Loadings & \\
Altitude & 0.82 \\
Vegetation cover & 0.81 \\
Human disturbance & -0.87 \\
Grazing condition & -0.67 \\
Eigenvalue & 2.52 \\
Proportion variation & 0.63
\end{tabular}

Loadings (correlations between the original variables and the eigenvectors), eigenvalues, and proportion of variation explained by the first principal component axis

mite infestation. In addition, males had a higher probability of mite infestation than females. In contrast, mite load was higher in males and individuals with lower body condition (Table 3, Fig. 2). Infestation probability and parasite load of mites were also associated with year: lizards captured in year 2015 had a higher infestation probability and higher parasite loads than in 2012 (Table 3).

Our analyses show that environmental factors explained the variation in tick infestation. The infestation probability of ticks was negatively correlated with PC1 (Table 3, Fig. 1), which suggests that lizards inhabiting grazed sites with higher human disturbance had a higher probability to be infested by ticks. Variation in tick loads was only related to year: lizards captured in 2015 had lower tick loads than in 2012 (Table 3).

\section{Co-occurrence of mites and ticks}

We retained 7 and 2 models to estimate relationships between two types of parasites for either their infestation probability or parasite load, respectively (Additional

Table 3 Relative importance and estimates for parameters predicting infestation probability and parasite load

\begin{tabular}{|c|c|c|c|c|c|c|}
\hline & \multicolumn{3}{|c|}{ Infestation probability } & \multicolumn{3}{|c|}{ Parasite load } \\
\hline & IM & COEF & SE & IM & COEF & SE \\
\hline \multicolumn{7}{|l|}{ Mites } \\
\hline PC1 & 0.85 & $0.21^{*}$ & 0.10 & 0.32 & 0.06 & 0.04 \\
\hline$T_{\max 6}$ & 0.62 & 0.17 & 0.10 & 0.23 & 0.01 & 0.04 \\
\hline Sex-m & 1.00 & $0.81 * * *$ & 0.19 & 0.84 & $0.33^{* * *}$ & 0.08 \\
\hline Body condition & 0.25 & 0.08 & 0.15 & 0.78 & $-0.29^{* * *}$ & 0.08 \\
\hline Year 2014 & 1.00 & $1.58^{* * *}$ & 0.23 & 0.51 & $0.44^{* *}$ & 0.13 \\
\hline Year 2015 & 1.00 & 0.41 & 0.27 & 0.51 & 0.22 & 0.15 \\
\hline \multicolumn{7}{|l|}{ Ticks } \\
\hline PC1 & 1.00 & $-0.52^{* * *}$ & 0.11 & 0.31 & -0.05 & 0.09 \\
\hline$T_{\max 6}$ & 0.68 & -0.17 & 0.09 & 0.31 & -0.04 & 0.06 \\
\hline Sex-m & 0.69 & 0.39 & 0.22 & 0.25 & 0.07 & 0.12 \\
\hline Body condition & 0.27 & 0.06 & 0.15 & 0.22 & -0.03 & 0.11 \\
\hline Year 2014 & 0.83 & 0.51 & 0.26 & 0.55 & 0.02 & 0.14 \\
\hline Year 2015 & 0.83 & $0.64^{*}$ & 0.26 & 0.55 & $-0.33^{*}$ & 0.16 \\
\hline
\end{tabular}

Upper panel: infestation probability and parasite load for mites; Lower panel: infestation probability and parasite load for ticks

IM relative importance, COEF coefficients, SE standard error, Sex-m male sex, $T_{\max 6}$ mean maximal temperature in June

Significant levels: ${ }^{*} P<0.05,{ }^{* *} P<0.01,{ }^{* * *} P<0.001$ 

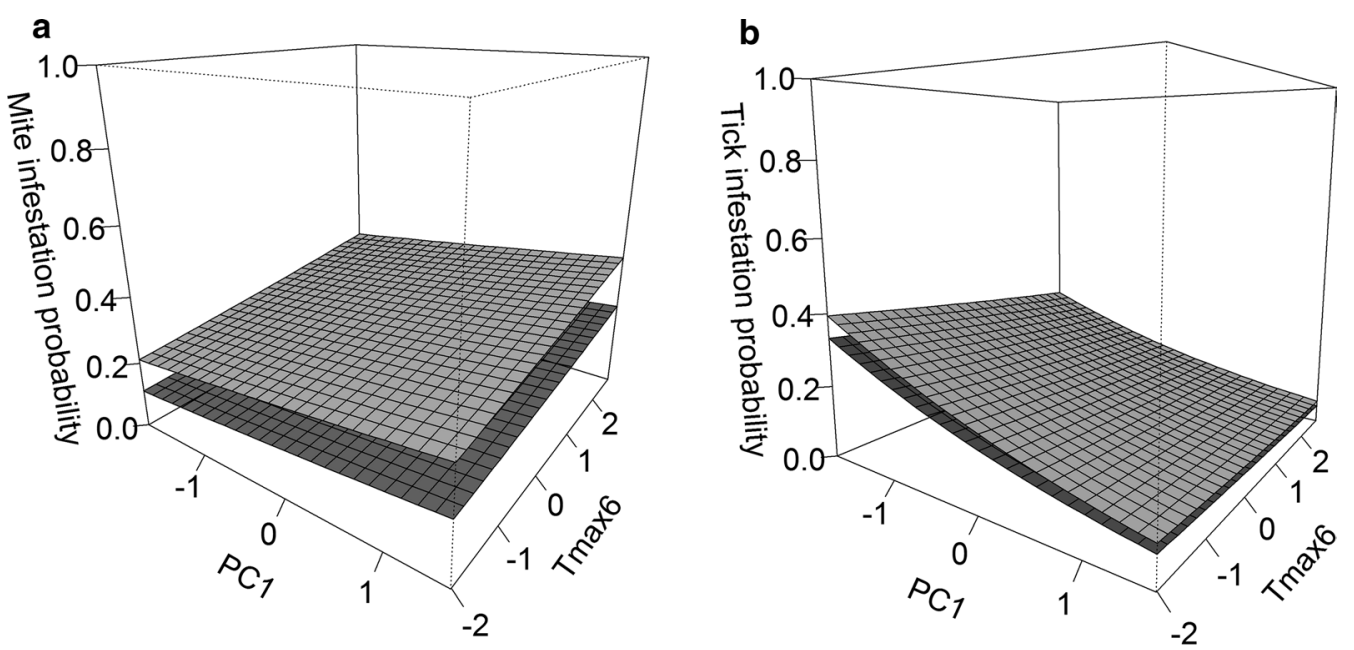

Sex

Male

Female

Fig. 1 Infestation probability of parasites in relation to environmental factors according to host sex. a Estimates of probability of mite infestation in relation to $\mathrm{PC} 1$ and $\mathrm{T}_{\max 6} ; \mathbf{b}$ estimates of probability of tick infestation in relation to $\mathrm{PC} 1$ and $\mathrm{T}_{\max 6}$. The infestation probability was the average value of three capture years

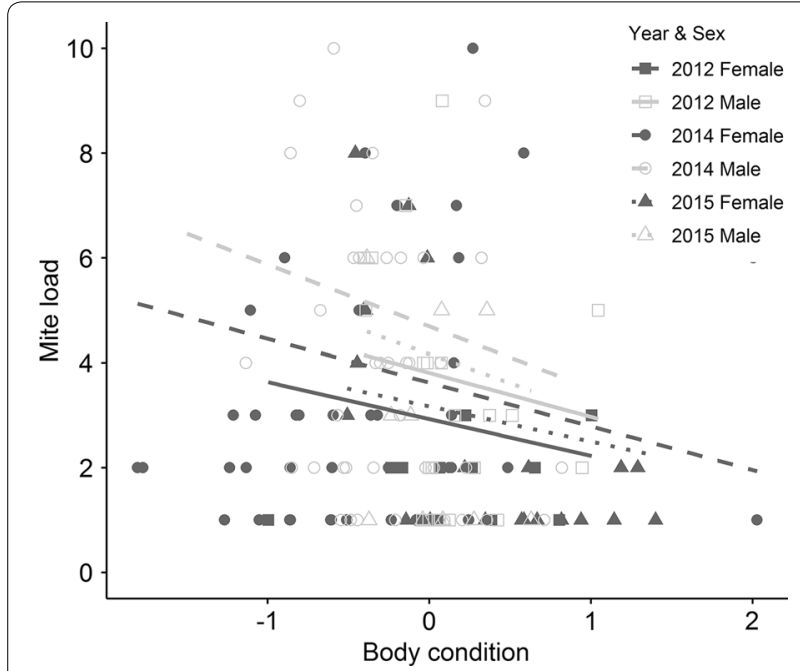

Fig. 2 Mite parasite load in relation to host body condition by year and host sex

file 1: Tables S5, S6). The probability of tick infestation was negatively associated with an interaction between mite infestation probability and PC1 (mite infestation probability $\times \mathrm{PC} 1, \quad$ estimate $=-0.89 \pm 0.31, \quad z=-2.90$, $P=0.004$, Fig. 3a). This result implies that mites can have a negative influence on ticks only through their interaction with the environment (PC1). In contrast, tick load, decreased with the interaction between mite load and PC1 (mite load $\times$ PC1: estimate $=-0.17 \pm 0.04$, $z=-3.70, P<0.001$, Fig. $3 \mathrm{~b})$. This result provides evidence that mite load had a direct, negative influence on tick load, and this relationship was mediated by the characteristics of the environment.

\section{Environments and competition between mites and ticks}

The piecewise SEM models for examining the probability of parasite infestation (Fisher's $C=3.97, \mathrm{df}=4$, $P=0.41$ ) and parasite load (Fisher's $C=2.76, \mathrm{df}=4$, $P=0.60)$ exhibited high goodness of fit values. When examining the probability of infestation, there was no evidence of competition between mites and ticks. However, we found that the probability of infestation by mites was negatively associated with the interaction between ticks and PC1 and similarly, ticks were negatively related to the interaction between mites and PC1 (Fig. 4a). Hence, when considering the probability of infestation, mites and ticks appear to have a mutual and negative effect on one another, but the interaction is mediated through variation in environmental characteristics. When we focused on parasite load, we detected direct negative relationships between mite load and tick load (Fig. 4b). The SEM also confirms that the probability of mite infestation and mite load were influenced by the sex and body condition of hosts (Fig. 4b). The results from the SEM indicate that environmental factors mediated the probability of 

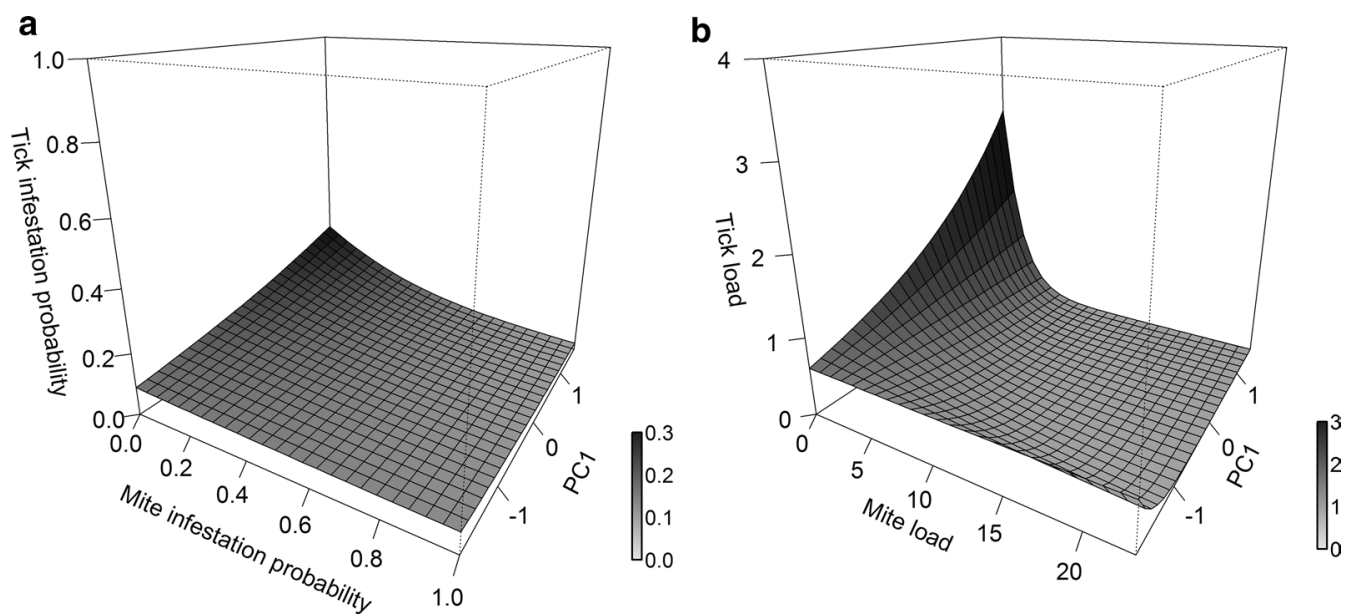

Fig. 3 The relationship between mites and ticks under the mediation of environmental factors. a The probability tick infestation in relation to the probability of mite infestation and $\mathrm{PC} 1 ; \mathbf{b}$ parasite load of ticks in relation to parasite load of mites and $\mathrm{PC} 1$

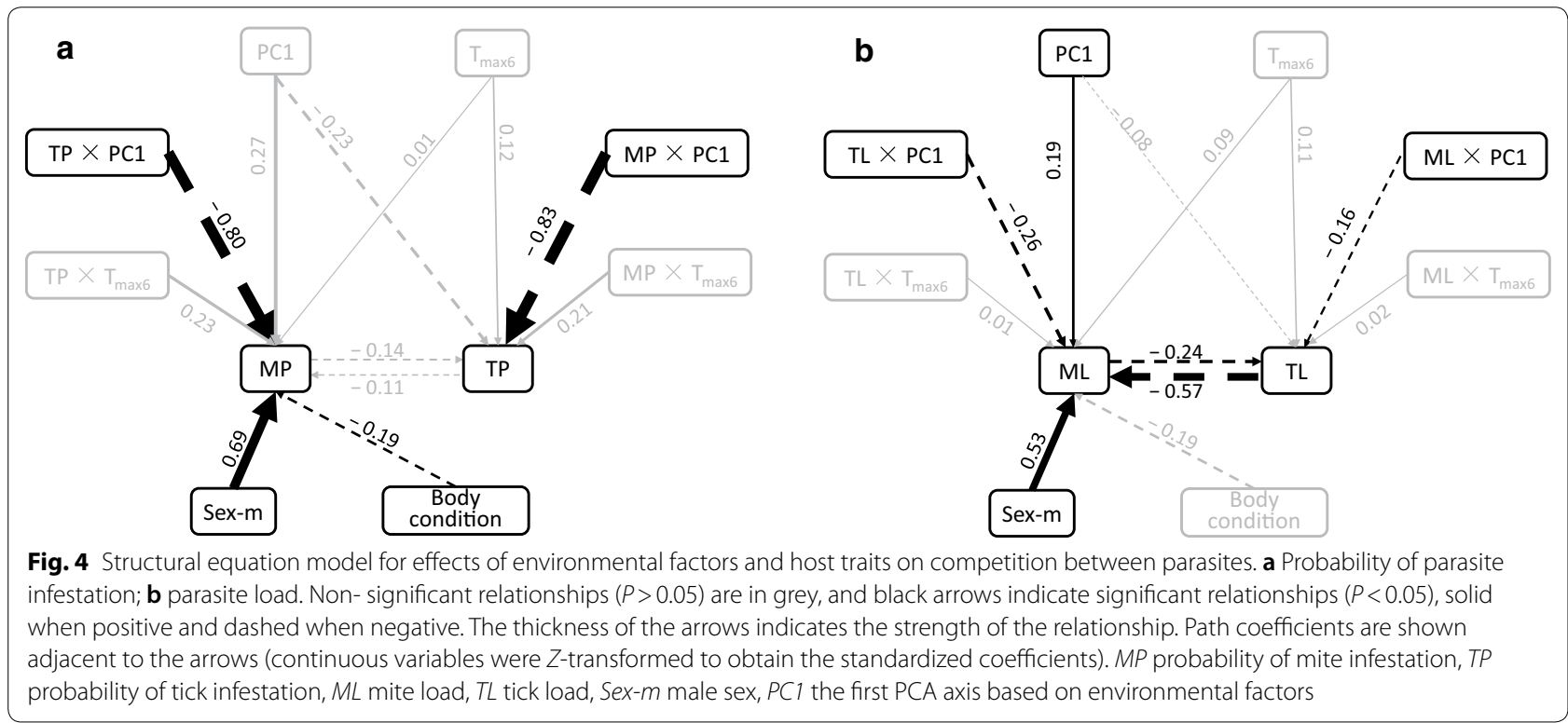

infestation (or parasite load) of two parasites in opposite directions, and the competition between mites and ticks depended on their relative parasite load.

\section{Discussion}

In this study, we investigated the variation in the probability of infestation and parasite load of two ectoparasites of the common lizard. We measured the patterns of parasitism from 12 different populations inhabiting sites that differed in several environmental factors. Our analyses show that environmental factors affected the probability of infestation by mites and ticks. However, these two ectoparasites exhibited divergent responses to prevailing environmental conditions among the sample sites. The probability of mite infestation was positively correlated with PC1, which suggests that populations at high altitude and high vegetation cover had a higher chance of being infested by mites. In contrast, tick infestation probability was negatively correlated with PC1, which suggests that populations in open habitats with high disturbance and grazing condition were more susceptible to ticks. Mite load was higher in males and in individuals with low body condition, but no such pattern was obtained for ticks. 
Influence of the environment on parasite infestation

Our results reflect the differences in the autecology of each ectoparasite. The probability of mite infestation increased in sites at high elevations with greater vegetation coverage, but lower anthropogenic disturbance. Spoecker and Zippel et al. [15, 29] showed that the pattern of an increase in mite prevalence with elevation might result from the lower temperatures and mesic characteristics of high altitude habitats, rather than the elevation per se. Thus, altitude might be a factor which encapsulates multiple elements, such as temperature, precipitation, relative humidity, and vegetation cover. Our results contradict this pattern, because we found no association between altitude and mean annual precipitation in study sites $(r=-0.14, P=0.72)$. However, the lack of a correlation is not unexpected, because the sites were selected for studying the effect of temperature and anthropogenic disturbance while minimizing the variation in other variables such as humidity.

Our analyses also reveal that higher plant cover correlated with a higher probability of infestation by mites. Parasite prevalence is often associated with habitat characteristics, such as vegetation structure [30]. Dense vegetation may provide sheltered microhabitats for parasites, therefore increasing local density, which can then result in higher rates of infestation of lizards [31]. In addition, these are the same microhabitats exploited by common lizards. Microclimate data will be needed to further investigate this hypothesis. However, the negative correlations between altitude and body condition $(r=-0.09$, $P=0.015)$ and between vegetation cover and body condition $(r=-0.13, P=0.0004)$ may provide other explanations. Given that mite infestations are greater in lizards with lower body condition (Table 3), the observed elevational and vegetational patterns may be a consequence of lizards with lower body condition inhabiting sites at higher altitude and great vegetation cover.

Patterns of tick infestation have been shown to be sensitive to the presence of large herbivores in grazed pastures. Adult female ticks require large animals as a host for their survival, reproduction, and maintenance of populations [24]. Therefore, the pattern of lizards having higher rates of infestation in grazed habitats might be explained by the enhanced survival and reproductive success of ticks in these areas. Hence, the abundance of larvae and nymphs available to feed on lizards should also be higher [32]. Another non-exclusive explanation is human disturbance per se. Increased anthropogenic disturbance such as human activity or tourism can more frequently stimulate the anti-predatory behavior of lizards and in turn reduce the energy allocated to their body condition and immune response [19]. We did not find support for this hypothesis since body condition was only weakly associated with human disturbance $(r=0.06, P=0.12)$. However, a subsequent experiment revealed that antipredatory behaviors of lizards exhibit a concomitant change with anthropogenic perturbations in our study sites (Qiang et al. unpublished data). It still remains to be investigated whether such behavioral changes result in a reduction of body condition and lowered immunity.

Finally, with the exception of five environmental factors examined above, the probability of mite and tick infestation varied among years in our populations. This suggests that other unmeasured abiotic or biotic factors also affect parasite prevalence. For example, humidity (including precipitation levels) [33], seasonality [34], and host population dynamics [35] can affect parasite prevalence in other species.

\section{Parasite infestation and host characteristics}

We found that the probability of mite infestation and mite load were higher in males than females. Male-biased infestation is common in many animal species and various explanations have been proposed in the literature [36]. For example, larger home ranges and increased mobility of males during the reproductive season is likely to raise the probability of encountering parasites [37, 38]. In addition, many other life history traits such as lifespan, mating system, behavior, social structure, immunity, and sex steroids are all potential explanations of malebiased infestations observed in our study [36, 39-41]. Androgens are known to affect parasite prevalence. For instance, high testosterone levels in males enhance their mating success, but is accompanied by a concomitant suppression of immune function, which may induce a higher infestation by parasites (i.e. the immune-competence handicap hypothesis) [39]. Testosterone also elicits more aggressive behaviors in individuals and results in a simultaneous higher cost of energy or even mortality, which might explain the higher susceptibility of males to parasite infestation [37]. The pattern of testosterone induced behavioral changes has partial supports in our study system as males are usually more aggressive than and dominant over females in common lizards [42]. However, there are also counter-examples on the role of testosterone, such as female-biased parasitism [43] and even opposite effects of testosterone on different types of parasites [44]. More detailed studies on the causal relationship between testosterone, aggressive behavior, and parasitism are therefore needed in this species to better understand differences between males and females in parasitism.

Irrespective of their sex, lizards with lower body condition were more susceptible to a higher mite load. In common lizards, individuals with poor body condition [45] usually have lower metabolic rates and may fail to express 
a strong immune response [46], and hence a higher accumulation of parasites. It may also be possible that parasites cause reductions in body condition of lizards, which in turn induces a higher infestations rate. Further manipulative experiments are needed to disentangle the underlying cause-effect relationship between host body condition and parasitism.

\section{Competition between mites and ticks}

Out of the 775 lizards examined, we found a small percentage $(\sim 4 \%)$ of individuals with a co-infestation of mites and ticks. This pattern reflects the differences in environmental factors associated with the life cycles of mites and ticks. We hypothesize that the difference in the natural history of these two ectoparasites decreases the opportunity for competition. Competition between mites and ticks might further be avoided as a result of microhabitat selection on the host: ticks mainly attach on the neck and around the forelimbs of lizards [38, 47], whereas mites occur on the ventral scales of lizards [48]. This explanation is consistent with our observations in common lizards. However, even if competition for habitat or space is unlikely, there might be competition for resources as both types of parasites feed on the blood of lizards. Our results point out a negative association for parasite load but not for infestation probability. This suggests that both types of parasites may infest the same host but once the host is in low body condition, only one type parasite seems to take advantage. However, the negative correlation of parasite load between the two types of parasites, although significant, was weak, and so this result should be interpreted with caution. Additionally, variation in the probability of tick infestation seems to be a consequence of indirect effects of the interplay between mites and environment, rather than a direct suppressive effect of mites (Fig. 4). This result confirms that the relationship between the two parasites was mediated by environmental factors, which attenuated the opportunity for competition. We suggest that when each parasite is regulated by distinct habitat constraints then competition among parasites has a rather weak effect on overall prevalence and parasite load.

\section{Conclusion}

We demonstrated that the probability of infestation by mites and ticks was mediated by divergent environmental factors. The distinct natural histories of these parasite species might explain why we found limited evidence for competition between them. The probability of infestation and parasite load of mites were influenced by the host sex and host body condition. Our results highlight the importance of how environmental variation and the autecology can mediate, to a large extent, the interaction between different types of parasites. We emphasize that further experimental manipulation should provide better inferences about the existence of competition between parasites.

\section{Methods \\ Study system}

The common lizard (Zootoca vivipara) is a small, viviparous lizard (adult snout-vent length varies from 40 to $60 \mathrm{~mm}$ in males and 45 to $75 \mathrm{~mm}$ in females) with a broad geographic distribution extending throughout Europe and Asia [49]. It inhabits mesic habitats, such as peat bogs, meadows, and heathlands. Males emerge from hibernation prior to females in late April-early May. Mating starts in early May following the emergence of females. Parturition occurs two and a half months later [27].

Our focal parasite speccies include mites of the genus Ophionyssus [26] and sheep ticks Ixodes ricinus. These two haematophagous arachnids have a free living stage in the soil and attach to a host for a blood meal [25]. They also have similar life cycles including larval, nymph, and adult stages [50, 51]. Ixodes ticks are sensitive to desiccation and their preferred habitats relate to multiple factors including vegetation cover, climate, and availability of hosts. In contrast, Ophionyssus mites are both thermophilic and hygrophilic [50,52]. The main hosts of ticks are large mammals such as deer, cattle, and sheep [24], whereas mites specialize on reptiles. Both ectoparasites are vectors for blood parasites $[25,53]$. In our study sites, $Z$. vivipara is the main reptile host of these two parasites. Other potential, alternative reptile hosts, e.g., sand lizards (Lacerta agilis) and snakes are found at low densities in our study sites.

\section{Lizard sampling, morphometrics and parasite collection}

We sampled lizards from twelve different sites (Fig. 5) in the Massif Central, France, in 2012, 2014, and 2015 (Table 4). The average date of capture was 26 June ( \pm 5 days). At each locality, between 15 and 25 females and 10 males were captured by hand and transported to a field laboratory. We measured body size (Snout-to-vent length, SVL $\pm 0.5 \mathrm{~mm}$ ) and body mass $( \pm 0.1 \mathrm{~g})$ of each lizard. We estimated body condition separately for each sex as the residuals from a linear regression of body mass versus SVL (males: intercept $=-3.31 \pm 0.35$, slope $=0.13 \pm 0.006, t=19.63, P<0.001$, adjusted $R^{2}=0.60 ;$ females: intercept $=-5.91 \pm 0.40$, slope $=0.17 \pm 0.006, t=26.64, P<0.001$, adjusted $\mathrm{R}^{2}=0.58$ ). Following capture, each lizard was visually examined for the presence of ectoparasites and numbers of mites and ticks were recorded. Mites always occurred under the ventral scales, whereas ticks tend to attach on the area behind the ear openings to the base of the neck and the forelimbs. 


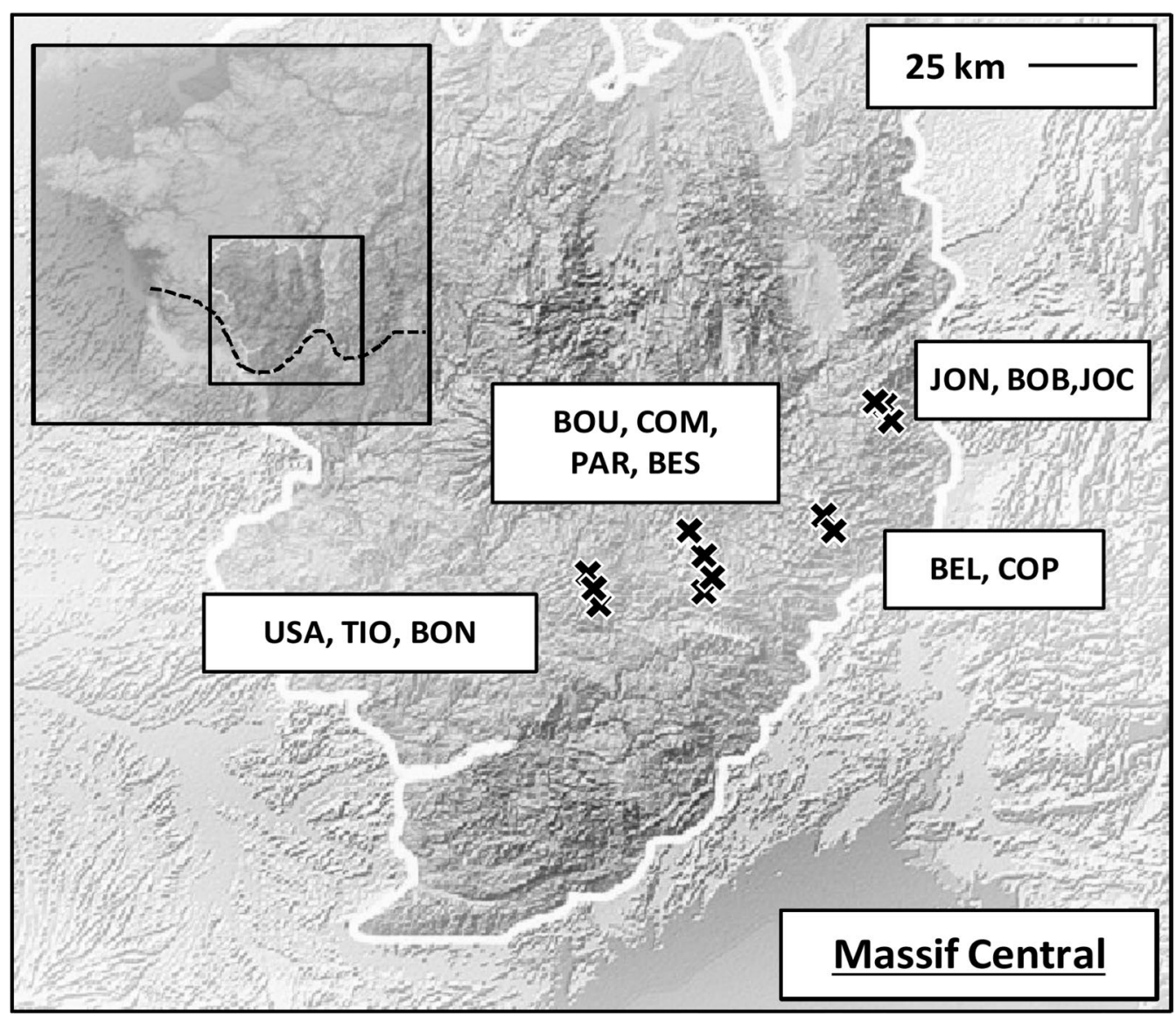

Fig. 5 Location of the sample sites in the Massif Central, France. The white line delineates the Massif Central. The dashed line represents the southern boundary of the distribution of viviparous common lizards (this map was modified from [54])

Table 4 Description of the study sites with related mountain range and environmental factors

\begin{tabular}{|c|c|c|c|c|c|c|c|c|}
\hline Site & Mountain range & SB & $\mathrm{N}$ & Alt (m) & $\mathrm{T}_{\max 6}\left({ }^{\circ} \mathrm{C}\right)$ & $\mathrm{VCl}$ & HD & G \\
\hline $\mathrm{BOB}$ & Mont du Vivarais & 2 & 68 & 1450 & 21.02 & 0.04 & 2 & 0 \\
\hline JOC & Mont du Vivarais & 1 & 40 & 1300 & 26.77 & 0.02 & 2 & 1 \\
\hline JON & Mont du Vivarais & 2 & 91 & 1405 & 22.86 & 0.19 & 2 & 0 \\
\hline BEL & Mont du Velay & 2 & 55 & 1350 & 18.82 & 0.30 & 1 & 0 \\
\hline COP & Mont du Velay & 3 & 86 & 1360 & 21.95 & 0.07 & 2 & 0 \\
\hline BON & Mont d'Aubrac & 1 & 34 & 1340 & 17.18 & 0.02 & 2 & 1 \\
\hline $\mathrm{TIO}$ & Mont d'Aubrac & 2 & 75 & 1300 & 17.96 & 0.00 & 2 & 1 \\
\hline USA & Mont d'Aubrac & 1 & 36 & 1210 & 15.85 & 0.05 & 3 & 1 \\
\hline BES & Margeride & 2 & 64 & 1220 & 21.63 & 0.10 & 3 & 1 \\
\hline $\mathrm{BOU}$ & Margeride & 2 & 72 & 1410 & 19.60 & 0.12 & 2 & 1 \\
\hline COM & Margeride & 3 & 80 & 1435 & 20.04 & 0.19 & 1 & 1 \\
\hline PAR & Margeride & 2 & 74 & 1415 & 20.57 & 0.32 & 1 & 0 \\
\hline
\end{tabular}

Each site is described with number of sampling bouts (SB), sample size (number of individuals, N) for each population (for a total of 775 lizards) and environmental factors including altitude (Alt), mean maximal temperature in June $\left(T_{\max }\right)$, vegetation cover index $(\mathrm{VCl})$, human disturbance (HD, 1 to 3 , with 1 being the least disturbed), and grazing condition (G: $0=$ ungrazed, $1=$ grazed) 


\section{Environmental correlates of parasite infestation}

At each capture site, we recorded the altitude, the maximum temperature during June $\left(\mathrm{T}_{\max 6}\right)$, an index of vegetation coverage, an index of anthropogenic disturbance, and the presence or absence of livestock (grazing). Altitude was the mean altitude of each site. The maximum temperature of June was based on measurements from the nearest meteorological station. However, as there was no unique meteorological station for each study site, we measured the local temperature of all sites by using temperature data loggers (Thermochron iButtons $\odot$, Waranet Solution, Auch, France, see Rutschmann et al. [55]). The final maximum June temperature in the analysis was predicted by the coefficients of a linear regression between temperature estimated by data loggers and those from the nearest meteorological station [55]. The vegetation cover index was derived from aerial photographs (scaled Google Earth $\odot$ views, Mountain View, CA, USA; the images were accessed on 11th Jan 2015) and calculated as the proportion of pixels representing trees or shrubs within the total capture area [55]. Our index of habitat disturbance involved a rank order from 1 to 4 , with 1 being the least disturbed site and 4 being the highest disturbed one. Grazing condition was represented by 0 or 1 , with 0 indicating no grazing and 1 indicating the presence of livestock on the site (we do not consider other ungulates such as the roe deer, Capreolus capreolus, because these species are uncommon at our sites).

\section{Statistical analysis \\ Influence of the environment on parasite infestation}

The variables we used to characterize the environment of each capture site have different scales of measurement. Thus, we used a principal components analysis (PCA) on four environmental factors (altitude, vegetation index, human disturbance and grazing condition) to generate new axes for describing differences among sites (Table 4, [55]). We extracted principal components from a correlation matrix using the function principal in the 'psych' package in R [56]. We determined the number of PC axes to retain based on the broken-stick method [57]. We used the PC axes to characterize the environmental features of each sample site.

We used the PC scores to investigate the relative roles of host phenotypic characteristics and environmental factors in structuring the susceptibility to parasitism on common lizards. Following the method of hurdle models [58], we used generalized linear models (GLM) to examine the probability of parasite infestation (Binomial distribution, uninfested vs. infested) and parasite load (zero-truncated Poisson distribution, the number of parasites found on an infested individual). We included the following predictor variables: the first PCA axis based on the environmental variables, $\mathrm{T}_{\max }$, year, sex, and body condition. We also performed a generalized linear mixed model (GLMM) analysis that used capture site as the random factor. When including all 3 years in the analysis, the GLMM model failed to converge. We attribute this to unbalanced sampling of some sites during 2015. We repeated the mixed model analysis, but excluded the data for these sites (110 lizards, accounting for 14\% of total sample size), and the model yielded similar results to the GLM. When needed, we also included a scale parameter [59] to compensate for the overdispersion of mite and tick loads in the model selection procedure (ratio between residual deviance and residual degrees of freedom, $\hat{c}=3.55$ and 1.29 respectively). We checked for the presence of multicollinearity among the variates by calculating the variance inflation factors (VIF) using the vif function in the car $\mathrm{R}$ package [60] following recommendations in Zuur et al. [61]. All variance inflation factors were below 3.0, which suggested no effects of multicollinearity.

We used the Akaike information criterion (AIC or to correct for overdispersion, QAIC) for model selection. When several models had similar AIC values, we conducted model averaging using the 'MuMIn' $\mathrm{R}$ package [62]. Two approaches to choose candidate models can be found in the literature: (1) when $\triangle \mathrm{AIC} \leq 2$ or (2) cumulative Akaike model weights $\leq 95 \%$. These two methods yielded similar results in our data, and we chose the latter one as it furnishes a more precise estimate of the support for each possible model (see more descriptions in [63]).

\section{Co-occurrence of mites and ticks}

We used generalized linear mixed models [64], with the infestation probability of ticks (or tick load) as the response variable and the infestation probability of mites (or mite load), the first environmental PC axis, $\mathrm{T}_{\max 6}$, and their interactions included as predictor variables. We added capture site as a random factor, and we also included an observational-level random factor in the parasite load model to account for the overdispersion. The selection of candidate models was based on their AIC values and with model averaging procedures aforementioned.

\section{Environments and competition between mites and ticks}

We used piecewise structural equation modeling (SEM) to explore the causal relationships between environmental factors, host traits, and potential competition between two parasites. We built models either for infestation probability or parasite load based on a priori observations and results, using the 'piecewiseSEM' package in $\mathrm{R}$ [65]. Compared to the traditional SEM, the piecewise 
SEM can account for the non-normal distribution of variables and random structure in models. Furthermore, the method allows a test of whether any paths are missing from the model by using Shipley's test of d-separation [66]. The goodness-of-fit of piecewise SEM was also evaluated with the akaike information criterion (AIC). The adequacy of overall fit is indicated by a non-significant $P$ value based on a Chi square test $(P>0.05)$ and AIC [67].

\section{Supplementary information}

Supplementary information accompanies this paper at https://doi. org/10.1186/s12898-019-0259-3.

Additional file 1. Additional tables.

\section{Abbreviations}

AIC: akaike information criterion; GLM: generalized linear model; GLMM: generalized linear mixed model; PCA: principle component analysis; PC1: first PCA axis; SEM: structural equation modeling; VIF: variance inflation factors.

\section{Acknowledgements}

We thank all the assistants who collected the data during this study. We thank two anonymous reviewers for their helpful comments on a previous version of this manuscript.

\section{Authors' contributions}

All authors collected data, QW and AR performed statistical analysis, QW and MR wrote the manuscript. DBM and JC led the project and commented on the manuscript. All authors read and approved the final manuscript.

\section{Funding}

Monitoring was financially supported by the 'Agence Nationale de la Recherche' (ANR 319 MOBIGEN), the 'Agence Nationale de la Recherche' (ANR MOBIGEN) and the Laboratoire d'Excellence TULIP (ANR-10-LABX-41). Q.WU is financially supported by China Scholarship Council (CSC) for his PhD study. D.B. Miles was supported by NSF Grant (EF128428). The funding body had no roles in the design of the experiment and collection, analysis, and interpretation of the data or the writing of the manuscript.

\section{Availability of data and materials}

The datasets used and analyzed during the current study are available from the corresponding author on reasonable request.

\section{Ethics approval and consent to participate}

Lizard sampling was approved by the 'Office National des Forêts', the 'Parc National des Cevennes' and three regional authorities (Auvergne, Rhône-Alpes, and Languedoc Roussillon). The study has also been approved by the Curie Ethics Committee.

\section{Consent for publication}

Not applicable.

\section{Competing interests}

The authors declare that they have no competing interests.

\section{Author details}

${ }^{1}$ CNRS, Station d'Ecologie Théorique et Expérimentale, UMR 5321 and Université Toulouse III-Paul Sabatier, 09200 Moulis, France. ${ }^{2}$ Université Fédérale Toulouse Midi-Pyrénées, 31013 Toulouse, France. ${ }^{3}$ School of Biological Sciences, University of Auckland, Auckland, New Zealand. ${ }^{4}$ Department of Biological Sciences, Ohio University, 131 Life Sciences Building, Athens, OH 45701, USA.

Received: 13 February 2019 Accepted: 10 October 2019 Published online: 22 October 2019

\section{References}

1. Poulin R. Evolutionary ecology of parasites. Princeton: Princeton University Press; 2011.

2. Sheldon BC, Verhulst S. Ecological immunology: costly parasite defences and trade-offs in evolutionary ecology. Trends Ecol Evol. 1996;11:317-21.

3. Schmid-Hempel P. Evolutionary parasitology: the integrated study of infections, immunology, ecology, and genetics. Oxford: Oxford University Press; 2011

4. Hamilton WD. Sex versus non-sex versus parasite. Oikos. 1980;35:282-90.

5. Daly EW, Johnson PT. Beyond immunity: quantifying the effects of host anti-parasite behavior on parasite transmission. Oecologia. 2011;165:1043-50.

6. Råberg L, Sim D, Read AF. Disentangling genetic variation for resistance and tolerance to infectious diseases in animals. Science. 2007:318:812-4.

7. Bulet P, Stöcklin R, Menin L. Anti-microbial peptides: from invertebrates to vertebrates. Immunol Rev. 2004;198:169-84.

8. Pedersen $A B$, Fenton A. Emphasizing the ecology in parasite community ecology. Trends Ecol Evol. 2007;22:133-9.

9. Rigaud T, Perrot-Minnot MJ, Brown MJ. Parasite and host assemblages: embracing the reality will improve our knowledge of parasite transmission and virulence. Proc R Soc B Biol Sci. 2010;277:3693-702.

10. Ebert D, Weisser WW. Optimal killing for obligate killers: the evolution of life histories and virulence of semelparous parasites. Proc R Soc B Biol Sci. 1997;264:985-91.

11. Krasnov BR, Burdelova NV, Khokhlova IS, Shenbrot Gl, Degen A. Larval interspecific competition in two flea species parasitic on the same rodent host. Ecol Entomol. 2005:30:146-55.

12. Read CP. The "crowding effect" in tapeworm infections. J Parasitol. 1951:37:174-8

13. Pollock NB, Gawne E, Taylor EN. Effects of temperature on feeding duration, success, and efficiency of larval western black-legged ticks (Acari: Ixodidae) on western fence lizards. Exp Appl Acarol. 2015;67:299-307.

14. Moyer BR, Drown DM, Clayton DH. Low humidity reduces ectoparasite pressure: implications for host life history evolution. Oikos. 2002;97:223-8.

15. Spoecker PD. Ectoparasites of a Mojave desert population of the lizard Uta stansburiana stejnegeri Schmidt. Am Midl Nat. 1967;77:539-42.

16. Tälleklint-Eisen L, Eisen RJ. Abundance of ticks (Acari: Ixodidae) infesting the western fence lizard, Sceloporus occidentalis, in relation to environmental factors. Exp Appl Acarol. 1999;23:731-40.

17. Harvell CD, Mitchell CE, Ward JR, Altizer S, Dobson AP, Ostfeld RS, Samuel MD. Climate warming and disease risks for terrestrial and marine biota. Science. 2002:296:2158-62.

18. Gillespie TR, Chapman CA. Forest fragmentation, the decline of an endangered primate, and changes in host-parasite interactions relative to an unfragmented forest. Am J Primatol. 2008;70:222-30.

19. Amo L, López P, Martí J. Nature-based tourism as a form of predation risk affects body condition and health state of Podarcis muralis lizards. Biol Conserv. 2006;131:402-9.

20. Pafilis P, Anastasiou I, Sagonas K, Valakos ED. Grazing by goats on islands affects the populations of an endemic Mediterranean lizard. J Zool. 2013;290:255-64.

21. Pettigrew M, Bull CM. The impact of heavy grazing on burrow choice in the pygmy bluetongue lizard, Tiliqua adelaidensis. Wildlife Res. 2011;38:299-306

22. Gottdenker NL, Streicker DG, Faust CL, Carroll CR. Anthropogenic land use change and infectious diseases: a review of the evidence. EcoHealth. 2014;11:619-32.

23. Brooks DR, Hoberg EP. How will global climate change affect parasitehost assemblages? Trends Parasitol. 2007;23:571-4

24. Gray JS, Dautel H, Estrada-Pena A, Kahl O, Lindgren E. Effects of climate change on ticks and tick-borne diseases in Europe. Interdiscip Perspect Infect Dis. 2009;2009:593232.

25. Cooper JE, Jackson OF. Diseases of the Reptilia. London: Academic Press; 1981.

26. Sorci G, Fraipont MD, Clobert J. Host density and ectoparasite avoidance in the common lizard (Lacerta vivipara). Oecologia. 1997;111:183-8.

27. Sorci G, Clobert J. Effects of maternal parasite load on offspring life-history traits in the common lizard (Lacerta vivipara). J Evol Biol. 1995;8:711-23. 
28. Sorci G, Massot M, Clobert J. Maternal parasite load increases sprint speed and philopatry in female offspring of the common lizard. Am Nat. 1994;144:153-64.

29. Zippel K, Powell R, Parmerlee J, Monks S, Lathrop A, Smith D. The distribution of larval Eutrombicula alfreddugesi (Acari:Trombiculidae) infesting Anolis lizards (Lacertilia: Polychrotidae) from different habitats on Hispaniola. Caribb J Sci. 1996;32:43-9.

30. Eisen R, Wright N. Landscape features associated with infection by a malaria parasite (Plasmodium mexicanum) and the importance of multiple scale studies. Parasitology. 2001;122:507-13.

31. García-ramírez A, Delgado-garcía JD, Foronda-rodríguez P, Abreu-acosta N. Haematozoans, mites and body condition in the oceanic island lizard Gallotia atlantica (Peters and Doria, 1882) (Reptilia: Lacertidae). J Nat Hist. 2005;39:1299-305.

32. Casher L, Lane R, Barrett R, Eisen L. Relative importance of lizards and mammals as hosts for ixodid ticks in northern California. Exp Appl Acarol. 2002;26:127-43.

33. Chilton NB, Bull CM. A comparison of the off-host survival times of larvae and nymphs of two species of reptile ticks. Int J Parasitol. 1993;23:693-6.

34. Altizer S, Dobson A, Hosseini P, Hudson P, Pascual M, Rohani P. Seasonality and the dynamics of infectious diseases. Ecol Lett. 2006;9:467-84.

35. Jones AR, Bull CM, Brook BW, Wells K, Pollock KH, Fordham DA. Tick exposure and extreme climate events impact survival and threaten the persistence of a long-lived lizard. J Anim Ecol. 2016;85:598-610.

36. Klein SL. The effects of hormones on sex differences in infection: from genes to behavior. Neurosci Biobehav Rev. 2000;24:627-38.

37. Salvador A, Veiga JP, Martin J, Lopez P, Abelenda M, Puertac M. The cost of producing a sexual signal: testosterone increases the susceptibility of male lizards to ectoparasitic infestation. Behav Ecol. 1996;7:145-50.

38. Bauwens D, Strijbosch H, Stumpel AHP. The lizards Lacerta agilis and $L$. vivipara as hosts to larvae and nymphs of the tick Ixodes ricinus. Holarctic Ecol. 1983;6:32-40.

39. Folstad I, Karter AJ. Parasites, bright males, and the immunocompetence handicap. Am Nat. 1992;139:603-22.

40. Bacelar FS, White A, Boots M. Life history and mating systems select for male biased parasitism mediated through natural selection and ecological feedbacks. J Theor Biol. 2011;269:131-7.

41. Silk MJ, Weber NL, Steward LC, Hodgson DJ, Boots M, Croft DP, Delahay RJ, McDonald RA. Contact networks structured by sex underpin sex-specific epidemiology of infection. Ecol Lett. 2018;21:309-18.

42. Le Galliard J-F, Fitze PS, Ferrière R, Clobert J. Sex ratio bias, male aggression, and population collapse in lizards. Proc Natl Acad Sci USA 2005;102:18231-6.

43. McCurdy DG, Shutler D, Mullie A, Forbes MR. Sex-biased parasitism of avian hosts: relations to blood parasite taxon and mating system. Oikos. 1998;82:303-12.

44. Fuxjager MJ, Foufopoulos J, Diaz-Uriarte R, Marler CA. Functionally opposing effects of testosterone on two different types of parasite: implications for the immunocompetence handicap hypothesis. Funct Ecol. 2011;25:132-8.

45. Oppliger A, Clobert J. Reduced tail regeneration in the common lizard, Lacerta vivipara, parasitized by blood parasites. Funct Ecol. 1997;11:652-5.

46. Meylan S, Richard M, Bauer S, Haussy C, Miles D. Costs of mounting an immune response during pregnancy in a lizard. Physiol Biochem Zool. 2012;86:127-36
47. Andrews RH, Petney TN. Competition for sites of attachment to hosts in three parapatric species of reptile tick. Oecologia. 1981;51:227-32.

48. Heredia VJ, Vicente N, Robles C, Halloy M. Mites in the Neotropical lizard Liolaemus pacha (Iguania: Liolaemidae): relation to body size, sex and season. S Am J Herpetol. 2014;9:14-9.

49. Pilorge T. Density, size structure, and reproductive characteristics of three populations of Lacerta vivipara (Sauria Lacertidae). Herpetologica. 1987:43:345-56.

50. Bannert B, Karaca H, Wohltmann A. Life cycle and parasitic interaction of the lizard-parasitizing mite Ophionyssus galloticolus (Acari: Gamasida: Macronyssidae), with remarks about the evolutionary consequences of parasitism in mites. Exp Appl Acarol. 2000;24:597-613.

51. Medlock JM, Hansford KM, Bormane A, Derdakova M, Estrada-Peña A, George J-C, Golovljova I, Jaenson TG, Jensen J-K, Jensen PM. Driving forces for changes in geographical distribution of Ixodes ricinus ticks in Europe. Parasite Vector. 2013;6:1.

52. Capinera JL. Encyclopedia of entomology. Berlin: Springer; 2008.

53. Gray JS. The development and seasonal activity of the tick Ixodes ricinus: a vector of Lyme borreliosis. Rev Med Vet Entomol. 1991;79:323-33.

54. Cévennes-Wikipedia. https://en.wikipedia.org/wiki/Cévennes\#/media/ File:MC_cevenes.jpg. Accessed 22 June 2016.

55. Rutschmann A, Miles DB, Galliard L, Richard M, Moulherat S, Sinervo B, Clobert J. Climate and habitat interact to shape the thermal reaction norms of breeding phenology across lizard populations. J Anim Ecol. 2016;85:457-66.

56. Revelle WR. psych: Procedures for personality and psychological research, Northwestern University, Evanston, Illinois, USA. URL https://CRAN.R-proje ct.org/package = psych. Version =1.7.8. 2017 .

57. Jackson DA. Stopping rules in principal components analysis: a comparison of heuristical and statistical approaches. Ecology. 1993;74:2204-14.

58. Dalrymple ML, Hudson IL, Ford RPK. Finite mixture, zero-inflated Poisson and hurdle models with application to SIDS. Comput Stat Data Anal. 2003:41:491-504.

59. Crawley M. The R book. New York: Wiley; 2007.

60. Fox J, Weisberg S. An R companion to applied regression. 2nd ed. Thousand Oaks: Sage; 2011.

61. Zuur AF, leno EN, Elphick CS. A protocol for data exploration to avoid common statistical problems. Methods Ecol Evol. 2010;1:3-14.

62. Barton K. MuMIn: multi-model inference. R package version 1. 40. 4. 2018.

63. Burnham KP, Anderson DR. Model selection and multimodel inference: a practical information-theoretic approach. New York: Springer; 2002.

64. Bolker BM, Brooks ME, Clark CJ, Geange SW, Poulsen JR, Stevens MH, White JS. Generalized linear mixed models: a practical guide for ecology and evolution. Trends Ecol Evol. 2009;24:127-35.

65. Lefcheck JS. piecewiseSEM: piecewise structural equation modelling in $R$ for ecology, evolution, and systematics. Methods Ecol Evol. 2016;7:573-9.

66. Shipley B. The AIC model selection method applied to path analytic models compared using a d-separation test. Ecology. 2013;94:560-4.

67. Shipley B. Confirmatory path analysis in a generalized multilevel context. Ecology. 2009;90:363-8.

\section{Publisher's Note}

Springer Nature remains neutral with regard to jurisdictional claims in published maps and institutional affiliations. 